\title{
Genipin Cross-Linked Nanocomposite Films for the Immobilization of Antimicrobial Agent
}

\author{
Avik Khan, ${ }^{\dagger}$ Stéphane Salmieri, ${ }^{\dagger}$ Carole Fraschini, ${ }^{\S}$ Jean Bouchard, ${ }^{\S}$ Bernard Riedl, ${ }^{\dagger}$ \\ and Monique Lacroix ${ }^{* \dagger}$
}

\footnotetext{
${ }^{\dagger}$ Research Laboratories in Sciences Applied to Food, Canadian Irradiation Centre (CIC), INRS-Institut Armand-Frappier, Université du Québec, 531 Boulevard des Prairies, Laval, Québec H7V 1B7, Canada

${ }^{\ddagger}$ Département des Sciences du Bois et de la Forêt, Faculté de Foresterie, Géographie et Géomatique, Université Laval, Québec City, Québec GIV 0A6, Canada

${ }^{\S}$ FPInnovations, 570 Boulevard St. Jean, Pointe-Claire, Québec H9R 3J9, Canada
}

ABSTRACT: Cellulose nanocrystal (CNC) reinforced chitosan based antimicrobial films were prepared by immobilizing nisin on the surface of the films. Nanocomposite films containing $18.65 \mu \mathrm{g} / \mathrm{cm}^{2}$ of nisin reduced the count of L. monocytogenes by $6.73 \mathrm{log} \mathrm{CFU} / \mathrm{g}$, compared to the control meat samples (8.54 log CFU/g) during storage at $4{ }^{\circ} \mathrm{C}$ in a Ready-To-Eat (RTE) meat system. Film formulations containing $9.33 \mu \mathrm{g} / \mathrm{cm}^{2}$ of nisin increased the lag phase of $L$. monocytogenes on meat by more than 21 days, whereas formulations with $18.65 \mu \mathrm{g} / \mathrm{cm}^{2}$ completely inhibited the growth of L. monocytogenes during storage. Genipin was used to cross-link and protect

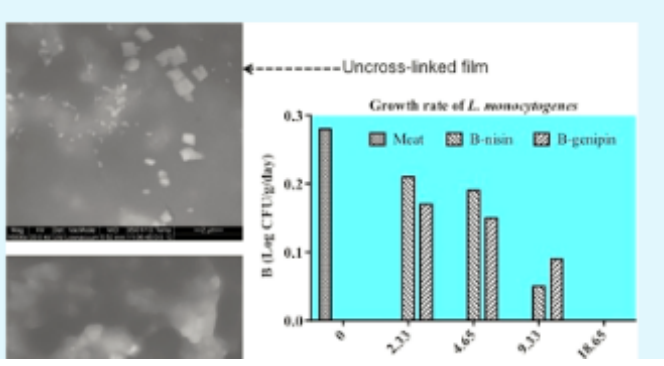

